\title{
A Educação Financeira e a Sua Influência na Tomada de Decisões
}

\author{
Financial Education and Its Influence on Decision-Making \\ Fabia Jaiany Viana de Souza \\ UFRN \\ Adriana Isabel Backes Steppan \\ UFRN \\ Maria das Vitórias de Macedo Farias \\ UFRN \\ Mauricio Correa da Silva \\ UFRN
}

\section{Resumo}

As Finanças Comportamentais determinam que algumas variáveis econômicas não podem ser descritas pelas condições de equilíbrio da teoria moderna, uma vez que os agentes financeiros tomam decisões muitas vezes incompatíveis com aquelas baseadas em expectativas racionais. Essa pesquisa consiste em verificar se os indivíduos que possuem conhecimento financeiro apresentam menos erros sistemáticos no processo de tomada de decisões. Para tanto, a metodologia adotada constitui-se de um estudo descritivo, tendo como finalidade investigar, através de uma analise qualitativa, a influência da educação financeira na tomada de decisões. Para a coleta de dados, realizou-se a aplicação aleatória de questionários que continham 6 problemas que foram replicados da investigação de Kaheman e Tversky (1979) junto a uma amostra composta por 154 estudantes que foram divididos em dois grupos distintos: Grupo 1, estudantes do curso de Ciências Contábeis, que são pessoas com uma boa instrução financeira, e Grupo 2, estudantes dos cursos de Letras e Ciências Sociais, indivíduos teoricamente com baixo nível de instrução financeira. Os resultados obtidos evidenciaram que o grupo que possuía uma melhor instrução financeira, assim como toda amostra, preferiu escolher as decisões que apresentavam um ganho mais certo, ao invés de analisar qual das alternativas propostas proporcionava maior retorno, e a partir dessa análise, tomar a melhor decisão. Diante dos resultados, pode-se concluir que a educação financeira não influenciou a tomada de decisão da amostra pesquisada, pois foi possível constatar a presença de erros sistemáticos no processo de tomada de decisão, mesmo no grupo que apresentava uma melhor instrução financeira.

Palavras-chave: Finanças comportamentais. Educação financeira. Tomada de decisões.

\begin{abstract}
The Behavioral Finance determine that some economic variables can not be described by the equilibrium conditions of the modern theory, as financial agents make decisions often incompatible with those based on rational expectations. This research is whether individuals who have financial knowledge have fewer systematic errors in decision-making. For this purpose, the methodology consists of a descriptive study, with the goal to investigate, through a qualitative analysis, the influence of education on financial decision making. For data collection, there was the random application of questionnaires that contained six problems that have been replicated in research Kaheman and Tversky (1979) along with a sample of 154 students were divided into two groups: Group 1, students course of Accounting, which are people with a good financial education, and Group 2 students of Arts and Social Sciences, theoretically individuals with low levels of financial literacy. The results showed that the group had a better financial education, as well as the entire sample, preferred to choose the decisions that had a more certain gain, rather than analyzing which of the proposals provided the greatest return, and from that analysis, make the best decision. Considering the results, it
\end{abstract}


can be concluded that financial education did not influence the decision making of the sample surveyed, it was possible to detect the presence of systematic errors in the process of decision making, even in the group that had a better financial education.

Keywords: Behavioral Finance. Financial Education. Decision-making.

\section{INTRODUÇÃO}

A hipótese de mercados eficientes é alicerçada na teoria da utilidade esperada e nas expectativas de origem racional. Estas duas constatações quando se combinam afirmam que os investidores são racionais, pois conhecem e organizam de maneira lógica suas preferências, buscando a maximização da utilidade de suas escolhas, e a atribuição com precisão de probabilidades aos eventos futuros, quando submetidos a escolhas que envolvam cenários de incertezas.

Vale salientar, que nas últimas décadas, os conceitos da hipótese de mercados eficientes apresentaram-se como insuficientes para explicar diversos fenômenos. Os estudos relacionados às Finanças Comportamentais foram se incorporando ao contexto de finanças nas últimas décadas como consequiência das anomalias irracionais ocasionadas pelas crises financeiras que não conseguiram ser explicadas pelo moderno modelo de finanças.

Enquanto que a teoria moderna de finanças tem como base a busca da maximização da utilidade esperada, as Finanças Comportamentais determinam que algumas variáveis econômicas não podem ser descritas pelas condições de equilíbrio da teoria moderna, uma vez que os agentes financeiros tomam decisões muitas vezes incompatíveis com aquelas baseadas em expectativas racionais.

Em virtude disso, verificar se os indivíduos que possuem conhecimento financeiro apresentam menos erros sistemáticos no processo de tomada de decisões, é importante para que se possa constatar se o estudo de modelos, cálculos, finanças, contabilidade e estatística aumenta a capacidade das pessoas em perceber probabilidades e compará-las diante de soluções de riscos, de modo que sejam diminuídos os vieses cognitivos e que sejam tomadas as melhores decisões.

Diante desse contexto, emerge a seguinte questão: Os indivíduos que possuem conhecimento financeiro apresentam menos erros sistemáticos no processo de tomada de decisões?

Essa pesquisa tem como objetivo geral verificar se os indivíduos que possuem conhecimento financeiro apresentam menos erros sistemáticos no processo de tomada de decisões.

A estrutura da pesquisa é constituída por cinco tópicos: este primeiro denominado introdução fornece uma visão geral a respeito do estudo, para isso, apresenta os objetivos, a justificativa e a estrutura do artigo. O segundo compreende o embasamento do estudo, sendo constituído, da apresentação dos conceitos da literatura existentes a cerca da Teoria Tradicional de Finanças, da Teoria Moderna de Finanças, e dos principais aspectos acerca das Finanças Comportamentais. O terceiro trata da metodologia que norteará a pesquisa. O quarto apresenta os resultados da pesquisa $\mathrm{O}$ quinto, considerações finais, contém as constatações obtidas no estudo.

\section{REFERENCIAL TEÓRICO}

R. Cont. Ufba, Salvador-Ba, v. 5, n. 2, p. 81-95, maio-agosto 2011 
Este tópico contém uma exposição dos principais aspectos conceituais necessários à compreensão do processo de educação financeira no processo de tomada de decisão. No primeiro momento, apresentam-se as abordagens mais relevantes da Teoria Tradicional de Finanças; em seguida, discuti-se a Teoria Moderna de Finanças, e por fim, são expostos os principais aspectos acerca das Finanças Comportamentais.

\subsection{Teoria Tradicional de Finanças}

A análise financeira tradicional tem como principal ferramenta à formação de carteiras de investimentos capazes de oferecer retornos superiores aos estabelecidos pelo mercado.

Os modelos de avaliação tradicional de ações tentam expor a existência de má precificação dos preços dos ativos, pelo mercado, fato esse, que possibilita ao investidor ganhar do mercado, através da incorporação ou eliminação da má precificação dos ativos, que possam ser identificados como subavaliados ou sobreavaliados, respectivamente (BUENO, 2002).

Para Macedo Júnior (2003), o que incentiva o estudo de finanças na teoria tradicional é a formação de portifólios que proporcionem retornos superiores aos índices médios de mercado. Assim, os investidores ativos são aqueles que administram uma carteira embasada nos fundamentos dessa teoria, pois procuram sempre vencer o mercado.

De acordo com Damodaran (1997) apud Macedo Júnior (2003), os observadores do mercado se concentram em suas previsões do mercado. Eles são conhecidos como analistas técnicos ou analistas gráficos, possuindo como instrumento de trabalho séries históricas de preços, que lhe permitem elaborar gráficos e projetar o comportamento da massa de investidores.

Ainda conforme o mesmo autor, os responsáveis pela seleção de títulos entendem que suas habilidades se concentram em achar títulos sub ou sobreavaliados. Eles são chamados de analistas fundamentalistas e seus alicerces de trabalho são as demonstrações contábeis e os planos de investimento da empresa e dos setores em que eles atuam.

Esses dois tipos de analistas estão presentes na mesma escola, pois apesar de discordarem nos métodos, pregam que o mercado pode ser previsto, e que, desse modo, é possível ganhar mais que o mercado.

Dessa forma, observa-se que essa teoria considera o mercado como sendo irracional e que este mercado nem sempre está correto (MEDEIROS, 2005). De acordo com ela, um mercado se comporta de forma irracional ou ineficiente, quando a maioria dos investidores, influenciados por uma onda de otimismo, pagam o que os ativos não valem, ou então, em caso contrário, direcionados por um pessimismo coletivo, não estão dispostos a pagar o que os ativos valem em relação ao seu fluxo de caixa descontado. Esse comportamento tem como consequiência, a possibilidades de serem formuladas estratégias de obtenção de sucesso através da formação de carteiras de investimentos capazes oferecer retornos superiores à média do mercado. (MACEDO, 2003; MEDEIROS, 2005; RAMOS, 2007).

Segundo Macedo Júnior (2003), as finanças tradicionais carecem de uma estrutura teórica consistente, pois não existe método de aplicação financeira que possa ser aplicado e que de forma sistemática gere uma rentabilidade superior à média do mercado. Com base neste fato, as finanças modernas recomendam que os investidores não tentem obter uma rentabilidade superior á do mercado e sim que procurem uma rentabilidade igual à do mercado ou uma rentabilidade de acordo com o nível de risco que o investidor esteja disposto a suportar. 


\subsection{Teoria Moderna de Finanças}

A teoria das finanças modernas teve seu desenvolvimento nos departamentos de economia das universidades, no inicio dos anos 50. Nesta época, a economia passava a ser fortemente influenciada pela teoria dos jogos, de Von Neumann e Morgestern (1944), que se baseava na premissa da racionalidade dos tomadores de decisão e afirmava que os mercados não poderiam ser previstos nem poderiam se comportar irracionalmente, e pelas suposições implícitas nesta teoria de que os agentes econômicos são racionais e os mercados são eficientes.

A característica mais marcante desse tipo de mercado é que o desempenho passado não é garantia de desempenho futuro. Como não existem padrões, não se podem utilizar informações passadas para a realização de previsões sobre o futuro (SANTOS e SANTOS, 2005).

A idéia de que os mercados pudessem se comportar de forma irracional contrariava os princípios da Teoria da Utilidade Esperada - TUE, proposta por Von Neumann em 1928. De acordo com esta teoria, em condições de incerteza, as pessoas racionais processam as informações objetivamente; consideram toda informação disponível e respondem a novas informações com base em um conjunto claramente definido de preferências.

Dessa forma, Von Neumann e Morgenstern (1944), através do artigo sobre a Teoria dos Jogos, consolidaram as idéias de comportamento econômico racional e da racionalidade na tomada de decisões econômicas (RAMOS, 2007).

Os principais conceitos da Teoria Moderna de Finanças, de acordo com Castro Júnior e Famá (2002), são a Teoria de Portfólio proposta por Markowitz (1952, 1959), a Hipótese de Eficiência de Mercados de Capitais (HEM) proposta por FAMÁ (1970) e o Modelo de Precificação de Ativos Financeiros (CAPM) desenvolvido por Sharpe (1963, 1964), Lintner (1965) e Black (1972), eles estão baseados em premissas que partem do pressuposto de que o investidor é racional, avesso ao risco e que utiliza a curva de utilidade para maximizar seu bem-estar.

O quadro 1 apresenta resumidamente as definições dessas teorias:

\begin{tabular}{|c|l|}
\hline & $\begin{array}{l}\text { A Moderna Teoria de Finanças determinou que a teoria da Utilidade Esperada fosse suficiente } \\
\text { para expor o comportamento dos agentes econômicos. De acordo com essa teoria, os agentes } \\
\text { respeitam uma série de premissas econômicas na tomada de decisões. Rogers, Favato e } \\
\text { Teoria da } \\
\text { Securato (2007) apontam que dentro da TUE, o } \\
\text { Esperada (TUE) } \\
\text { investidor é racional e avalia o risco conforme a mudança que o mesmo poderá propiciar em } \\
\text { seu nível de riqueza. Dessa forma, o investidor conhece e organiza de forma lógica suas } \\
\text { predileções, buscando maximizar a "utilidade" de suas escolhas, atribuindo assim, com } \\
\text { exatidão, probabilidades aos eventos futuros, quando estes estiverem subordinados a escolhas } \\
\text { que envolvam incertezas e risco. }\end{array}$ \\
\hline $\begin{array}{l}\text { A Moderna } \\
\text { Teoria de }\end{array}$ & $\begin{array}{l}\text { A moderna teoria do portfólio postula que, todos os investimentos podem ser reduzidos ao } \\
\text { binômio risco-retorno e, que o risco é compensado pela diversificação. Para Haugen (2000) na } \\
\text { moderna teoria do portfólio, o retorno esperado de um investimento é a média aritmética } \\
\text { Markowitz } \\
\text { ponderada esperada de todos os retornos que compõe a carteira. E, o risco da carteira, pode ser } \\
\text { representado pela dispersão de seus retornos em relação ao seu retorno esperado. }\end{array}$ \\
\hline $\begin{array}{l}\text { A Hipótese de } \\
\text { Eficiência de } \\
\text { Mercados de }\end{array}$ & $\begin{array}{l}\text { A HEM tem sido a hipótese central na área de finanças por quase 40 anos. Esta teoria } \\
\text { fundamenta-se na teoria da utilidade esperada e nas expectativas racionais. Estas duas } \\
\text { proposições combinadas afirmam que os indivíduos/ investidores são considerados racionais, } \\
\text { conhecem e ordenam de forma lógica suas preferências, buscam maximizar a "utilidade" de } \\
\text { suas escolhas, e conseguem atribuir com precisão probabilidades aos eventos futuros, quando } \\
\text { submetidos a escolhas que } \\
\text { envolvam incertezas. }\end{array}$ \\
\hline $\begin{array}{l}\text { Modelo de } \\
\text { Precificação de }\end{array}$ & $\begin{array}{l}\text { Segundo Haugen (1997) esta teoria baseia-se na maneira como as ações são precificadas em } \\
\text { relação ao seu risco e se fundamenta no pressuposto de que, todos os investidores empregam a }\end{array}$ \\
\hline
\end{tabular}




\begin{tabular}{|l|l|}
\hline \multicolumn{1}{|c|}{ Ativos de } & teoria do Portfólio de Markowitz, para encontrar portfólios na fronteira eficiente dependendo \\
Capital - CAPM & da aversão ao risco individual. Dessa forma, todos os ativos deveriam estar dispostos sobre \\
uma linha reta num gráfico, risco versus retorno, denominada como linha do mercado de \\
títulos, a qual \\
cruza o eixo Y no ponto chamado Risk Free, o qual representa o retorno sobre um ativo livre \\
de risco. E, a linha que liga o Risk Free ao ponto (Retorno da carteira de mercado (Rm) x \\
Coeficiente $\beta$ ) define a linha do mercado de títulos. O CAPM postula que as taxas de retorno \\
em equilíbrio dos ativos de risco são uma função de suas co-variâncias com a carteira de \\
mercado.
\end{tabular}

Quadro 1 - Principais Conceitos da Moderna Teoria de Finanças.

Fonte: Costa et. al. (2008).

De acordo Costa e. al (2008) todas essas teorias e hipóteses se baseiam na teoria econômica neoclássica, que possui como principal vertente um mundo composto por agentes capazes de decidir estritamente de acordo com uma racionalidade ilimitada e metodologicamente estruturada de acordo com a Teoria da Utilidade Esperada (TUE) e sem vieses acerca do futuro.

Dessa forma, o comportamento humano perante decisões sob incerteza, tem como alicerce o comportamento econômico racional, de forma que os aspectos psicológicos são ignorados dentro desse arcabouço.

Para Macedo Júnior (2003) as primeiras críticas a essa teoria foram realizadas a partir de constatações que demonstraram que os preços de alguns ativos, em determinados momentos, poderiam apresentar tendências ou anomalias, fato que contraria a hipótese de eficiência de mercado, anomalias que representam uma evidência de comportamento que contradiz a previsão da teoria aceita, no caso da moderna teoria, a de eficiência de mercados.

Ainda para o mesmo autor apresenta como segunda critica as finanças modernas uma constatação que partiu dos pesquisadores que testavam a racionalidade dos tomadores de decisão. Tversky e Kahneman (1979) identificaram várias situações em que o ser humano tomava decisões baseadas em vieses que os afastavam da racionalidade, o que contraria os pressupostos da moderna teoria.

Simom (1957) apud Carvalho Júnior, Rocha e Bruni (2009) verificou que as pessoas não analisam todas as alternativas antes de tomar uma decisão. Eles suspendem a busca por uma alternativa ótima tão logo encontrem uma alternativa satisfatória. Isto contraria o pressuposto de que os investidores comparam e ordenam todas as alternativas de investimentos possíveis antes de decidir.

Ainda conforme o mesmo autor, a moderna teoria não oferece nenhuma característica psicológica ao comportamento humano, o que é evidenciado pela limitada capacidade descritiva e preditiva desta teoria.

Estudos relacionados com a área da psicologia são aplicados ao mercado financeiro para explicar os comportamentos não previstos pela TUE, e as aplicações são atualmente chamadas de Finanças Comportamentais.

Essa nova área de finanças estuda o comportamento dos indivíduos, especificamente no processo de tomada de decisão e considera que os indivíduos não agem sempre racionalmente e muitas vezes são influenciados por falhas cognitivas. Dentre as principais linhas de estudo está a determinação e a compreensão das falhas cognitivas, bem como suas implicações.

\subsection{Finanças Comportamentais}

As Finanças Comportamentais tem como finalidade identificar e compreender as ilusões cognitivas que fazem com que pessoas cometam erros sistemáticos de avaliação de valores, 
probabilidades e riscos. Elas consideram que os indivíduos nem sempre agem racionalmente, pois estão propensos aos efeitos das ilusões cognitivas.

No ano de 1979, Daniel Kahneman e Amos Tversky publicaram um artigo na Econometrica em que relataram suas pesquisas referentes à interferência de estruturas mentais em tomada de decisões para escolhas simples com resultados monetários e probabilidades declaradas.

Daniel Kahneman recebeu o Prêmio Nobel de Economia em 2002, mesmo não sendo economista. Os estudos destes psicólogos entre os anos 1974 e 1979, representam a baseteórica para a análise do comportamento de investidores, o comportamento e o processo de tomada de decisão do ser humano em situações de risco, desenvolvendo papel fundamental para o início do desenvolvimento das finanças comportamentais.

Nesse trabalho, os pesquisadores fizeram uma crítica à teoria da utilidade esperada como modelo descritivo de tomada de decisões sob risco e desenvolveram um modelo alternativo, chamado de Teoria do Prospecto.

Utilizando problemas ou prospectos arriscados, eles testaram a validade da teoria da utilidade esperada e obtiveram vários padrões de comportamento que são inconsistentes com os princípios dessa teoria. (MACEDO JÚNIOR, 2003).

Essa teoria, diferentemente da teoria neoclássica, sustenta que as escolhas dos indivíduos dependem da forma como as opções são apresentadas (frame dependence). Expressão disso seria a "contabilidade mental" (mental accounting), que se refere à tendência das pessoas de compartimentarem mentalmente os eventos com base em atributos superficiais e episódicos (ALDRIGHI e MILANEZ, 2005).

De acordo com Milanez (2003), as características humanas que afetam o homem econômico são decorrentes de vieses do processo de tomada de decisão, entre eles, efeito certeza, efeito isolamento, padrões históricos, ilusão de controle ou conhecimento, perseverança, sobre-reação ás novidades do mercado, aversão á perda, excesso de confiança e otimismo, representatividade, ancoragem e disponibilidade.

No efeito certeza, as pessoas tendem a dar maior peso às possibilidades que têm alta probabilidade de acontecer; este comportamento dos agentes viola o axioma da substituição da TUE (ALDRIGHI e MILANEZ, 2005). Através de suas pesquisas, Kahneman e Tversky (1979), chegaram à conclusão que os prospectos com 100\% de certeza são excessivamente valorizados em comparação com os prospectos que envolvem alguma incerteza (mesmo oferecendo um ganho maior), diferentemente do que pressupõe a TUE. Em contrapartida, os indivíduos preferem uma perda com probabilidade de ocorrência inferior a $100 \%$ a uma perda certa ainda que menor. O viés psicológico de valorização excessiva da certeza traduz-se em maior aversão ao risco no domínio dos prospectos positivos e em maior propensão ao risco no domínio das expectativas de perdas.

O efeito isolamento é visualizado quando necessita-se simplificar o processo de tomada de decisão (de escolha), as pessoas geralmente desconsideram boa parte das características de cada uma das opções, ignorando os aspectos comuns, e centralizam sua análise sobre os componentes que distinguem as opções de escolha. Como há diferentes formas de decompor as opções em partes comuns e distintas, as escolhas podem variar conforme o tipo particular de decomposição, gerando preferências inconsistentes (MILANEZ, 2003; ALDRIGHI e MILANEZ, 2005).

Segundo Milanez (2003), os padrões históricos ocorrem quando uma escala de valor é fixada ou demarcada por observações recentes. Isto pode levar investidores a esperar ganhos de uma companhia a se comportarem como no passado, conduzindo a um erro de previsão. $\mathrm{Na}$ verdade, pode-se dizer que isto é o chamado determinismo histórico, tendência a acreditar que 
eventos históricos poderiam ser antecipados pelas pessoas que os vivenciaram ou que pelo menos as pessoas teriam boas chances de prever tais eventos.

A ilusão de controle ou o conhecimento podem ser observados quando as pessoas têm a tendência a acreditar que a acurácia de suas previsões será tanto maior quanto maior forem as informações a respeito do evento futuro (MILANEZ, 2003). É ampla a crença de que as previsões serão mais precisas quanto maior a quantidade de informações levantada; entretanto, quantidade de informações não implica maior possibilidade de prever corretamente, pois não necessariamente as novas informações são melhores que as já existentes, quando na verdade é a qualidade dessas que afeta a precisão da previsão. A ilusão de controle é uma tendência dos investidores em acreditarem que podem controlar uma determinada situação, mesmo quando isso é completamente impossível. Este viés poderá levar o investidor a negociar com grande frequiência, talvez porque acredite que esteja interpretando o mercado melhor do que os outros.

A perseverança é encontrada quando existe uma série de estudos que comprova que as pessoas freqüentemente têm opinião formada, o que provoca dois efeitos: elas relutam em procurar evidências que contrariem suas crenças e ao encontrá-las, consideram-nas com excesso de ceticismo (YOSHINAGA et al, 2004). No contexto acadêmico de Finanças, Thaler e Barberis (2003) observam com ironia que, embora muito já tenha se demonstrado contra a HME, não são poucos ou teóricos que permanecem firmes à sua crença de que os mercados são eficientes.

A sobre-reação de mercado surge quando variáveis financeiras, como por exemplo, preços e volatilidades, distanciam-se excessivamente de seus valores intrínsecos. Assim, a heurística da representatividade pode estar associada à sobre-reação. Dessa forma, as notícias de desempenho passado, bom ou ruim, de uma empresa podem influenciar o processo de tomada de decisão, causando, respectivamente, euforia ou desânimo excessivo e provocando uma sobre-reação do mercado (KIMURA, 2003).

O modelo de aversão á perda diz que o investidor pondera tanto os ganhos quanto as perdas, mas não dá a ambos o mesmo valor psicológico (OLIVEIRA, SILVA E SILVA, 2005). A proposta feita por Kahneman e Tverski (1979) é que esse conceito baseia-se na constatação de que as pessoas sentem muito mais a dor da perda do que o prazer obtido com um ganho equivalente; ou seja, as pessoas não têm aversão ao risco e sim à perda. Diante da perda, as pessoas assumem riscos somente pela chance de não realizar a perda, ou seja, com relação aos ganhos, as pessoas são avessas ao risco, mas diante da possibilidade de perder, as pessoas são avessas à perda (HALFELD e TORRES, 2001).

Nenhum outro problema de julgamento e tomada de decisão tem maior poder de catástrofe do que o excesso de confiança. Ele pode levar o investidor a crer que possui vantagens comparativas na análise e avaliação de ativos em relação ao mercado, mantendo posições perdedoras. Além disso, o excesso de confiança pode levar a demasiada exposição em determinados ativos, tendo em vista a crença viesada do investidor em que seu posicionamento no ativo conduzirá a ganhos futuros consideráveis. Neste contexto, pode haver uma diversificação de investimentos inadequada, devido à concentração da carteira em determinados ativos. Autoconfiança e otimismo excessivos estariam associados aos mecanismos de defesa do ego, que tentam manter a harmonia entre crenças e atitudes: os erros normalmente são atribuídos a fatores não controláveis (má sorte, interferência dos outros etc.), enquanto o sucesso resultaria da habilidade do investidor (ALDRIGHI e MILANEZ,2005). Assim, acreditamos que as falhas geralmente são decorrentes de erros de outras pessoas, a má sorte ou a outros fatores não controláveis, ao mesmo tempo em que os sucessos são devidos à nossa habilidade individual. 
A heurística da representatividade (representativeness heuristic) designa o predomínio da influência de estereótipos irrelevantes ou de analogias ingênuas nas decisões dos indivíduos sob incerteza (ALDRIGHI e MILANEZ, 2005). No caso de investimentos, a heurística da representatividade pode influenciar a percepção dos investidores sobre o potencial de valorização de uma ação. Investidores podem avaliar positivamente o potencial de uma ação específica simplesmente em função de terem formado uma opinião estereotipada sobre a empresa. Esta visão pode ser conseqüência da simpatia pela empresa, do desempenho passado da empresa ou de informações obtidas através de outros investidores ou meios de comunicação (KIMURA, 2003).

Pela "heurística da disponibilidade" (availability heuristic) as pessoas "estimam a freqüência de uma classe ou a probabilidade de um evento pela facilidade com que instâncias ou ocorrências podem ser trazidas à mente" (KAHNEMAN E TVERSKY, 1979). Os vieses de disponibilidade estão relacionados com o fato de que os eventos mais freqüentes são mais facilmente relembrados que os demais, e que os eventos mais prováveis são mais lembrados que os improváveis (YOSHINAGA et al, 2004). Seus julgamentos seriam, portanto, bastante influenciados pela facilidade com que as ocorrências de eventos podem ser lembradas ou resgatadas por livre associação: pela sua visibilidade, exposição, e saliência. Eventos mais recentes, mais familiares, ou que julgamos mais importantes têm uma maior probabilidade de serem recuperados pela memória (ALDRIGHI e MILANEZ,2005).

Segundo Milanez (2003) os vieses cognitivos podem não desaparecer mesmo com a educação financeira dos investidores. Ele afirma que os indivíduos tendem a exibir excessiva confiança em suas atitudes e ignoram fatos contrários às suas crenças preliminares, principalmente em momentos de excessivo otimismo (bolhas especulativas) ou pessimismo (pânicos).

No Brasil, existem poucas informações sobre como operar em mercados de capitais e quase nada sobre vieses cognitivos. Mesmo programas educacionais nos EUA não consideram importante alertar os investidores a respeito dos vieses cognitivos a que estão sujeitos e muito menos à potencial ação oportunista de outros agentes, tais como emissores de ações, empresas, corretores, que percebem tais erros. Nesse sentido, "o efeito educação financeira" não teria influência na tomada de decisões em investimentos, e programas educacionais que alertassem sobre esse os tipos de efeitos e outros potenciais vieses cognitivos, não melhorariam a alocação dos recursos ou ajudariam investidores a

cometer menos erros em suas decisões de investimento. (ROGERS; FAVATO; SECURATO).

\section{METODOLOGIA}

A pesquisa foi desenvolvida considerando uma análise qualitativa da educação financeira dos indivíduos na minimização dos erros sistemáticos no processo de tomada de decisões.

Quanto aos fins, considerando a natureza da problemática da pesquisa, esse estudo é do tipo descritivo, tendo como finalidade apresentar e estudar as características de uma determinada amostra. Nessa pesquisa é investigado se os indivíduos que possuem conhecimento financeiro apresentam menos erros sistemáticos no processo de tomada de decisões.

Quanto aos meios, para atingir os objetivos e obter a resposta do problema, realizou-se uma pesquisa bibliográfica para fornecer embasamento teórico sobre o tema.

Para essa pesquisa foi necessária coleta de dados junto a estudantes da Universidade Federal do Rio Grande do Norte - UFRN que foram submetidos aleatoriamente aos questionários utilizados na pesquisa. A amostra foi composta por 154 estudantes que foram divididos em dois grupos distintos: Grupo 1, 76 estudantes do curso de Ciências Contábeis, 
que são pessoas com uma boa instrução financeira, e Grupo 2, 78 estudantes dos cursos de Letras e Ciências Sociais, indivíduos teoricamente com baixo nível de instrução financeira

Como instrumento de pesquisa foram utilizados problemas utilizados por Kahneman e Tversky (1979) para a elaboração do artigo seminal que aborda a Teoria do Prospecto. Dos 16 problemas utilizados para essa pesquisa, foram selecionados 6 prospectos que pudessem evidenciar que os indivíduos deveriam analisar qual das alternativas propostas proporciona o maior retorno, e a partir dessa observação, escolher a melhor decisão, ao invés de optar por ganhos certos.

Como resultado tiveram-se dados que serviram para encontrar o resultado dos respondentes para cada prospecto utilizado na pesquisa, identificar a freqüência das decisões dos respondentes de cada grupo para os problemas analisados, e ainda, possibilitaram analisar se a tomada de decisão dos respondentes foi influenciada pelo conhecimento financeiro.

Todas as informações coletadas ajudaram na pesquisa, no entanto, para serem utilizadas precisaram ser trabalhadas, para isso foram lidas e das mesmas extraídas sua essência, em alguns casos, em outros, devido sua importância, foram retiradas em sua totalidade.

\section{ANÁLISE DE DADOS}

Pesquisas realizadas por estudiosos da Psicologia têm demonstrado que a presença de vieses permanece mesmo em situações em que aos indivíduos são oferecidos grandes incentivos, grande conhecimento a respeito da situação apresentada, entre outras situações que deveriam atenuar a ocorrência de erros sistemáticos na tomada de decisões.

Dessa forma, esse estudo procurou replicar algumas questões da investigação de Kahneman e Tversky (1979), que aborda a Teoria do Prospecto. Para isso, o questionário de pesquisa foi aplicado em 154 respondentes que foram divididos em dois grupos: GRUPO 1, pessoas que possuem teoricamente um conhecimento de finanças, e GRUPO 2, pessoas com baixo nível de instrução financeira.

O Quadro 2 apresenta a freqüências das respostas da amostra geral analisada, os seja, foram somadas as respostas do GRUPO 1 com o GRUPO 2, para se chegar ao valor total de respondentes do questionário.

\begin{tabular}{|c|c|c|c|c|}
\hline \multicolumn{5}{|c|}{ FREQUÊNCIA DOS PROPECTOS NA PESQUISA } \\
\hline PROBLEMA & PROSPECTO & $\begin{array}{c}\text { FREQUÊNCIA } \\
\text { ABSOLUTA }\end{array}$ & $\begin{array}{c}\text { FREQUENCIA } \\
\text { RELATIVA }\end{array}$ & $\begin{array}{c}\text { FREQUENCIA } \\
\text { PERCENTUAL } \\
(\%)\end{array}$ \\
\hline 1 & $\begin{array}{l}\text { A: }(\$ 2500: 33 \% ; \$ 2400: 66 \% ; \\
\$ 0: 1 \%) \\
\text { B: }(\$ 2400: 100 \%)\end{array}$ & $\begin{array}{c}37 \\
117\end{array}$ & $\begin{array}{l}0,24 \\
0,76\end{array}$ & $\begin{array}{l}24 \\
76\end{array}$ \\
\hline 2 & $\begin{array}{l}\text { A:(\$2500:33\%:\$0:67\%) } \\
\text { B:(\$2400:34\%;\$0:66\%) }\end{array}$ & $\begin{array}{l}65 \\
89 \\
\end{array}$ & $\begin{array}{l}0,42 \\
0,58\end{array}$ & $\begin{array}{l}42 \\
58\end{array}$ \\
\hline 3 & $\begin{array}{l}\text { A:(\$4000:80\%;\$0:20\%) } \\
\text { B:(\$3000:100\%) }\end{array}$ & $\begin{array}{c}30 \\
124 \\
\end{array}$ & $\begin{array}{l}0,19 \\
0,81\end{array}$ & $\begin{array}{l}19 \\
81\end{array}$ \\
\hline 4 & $\begin{array}{l}\text { A: }(-\$ 4000: 80 \% ; \$ 0: 20 \%) \\
\text { B: }(-\$ 3000: 100 \%)\end{array}$ & $\begin{array}{c}100 \\
54\end{array}$ & $\begin{array}{l}0,65 \\
0,35\end{array}$ & $\begin{array}{l}65 \\
35\end{array}$ \\
\hline \multirow[t]{2}{*}{5} & $\begin{array}{l}\text { A: (Viagem de três semanas para } \\
\text { Inglaterra, } \\
\text { França e Itália: } 50 \% \text {;Nada: } 50 \% \text { ). }\end{array}$ & 30 & 0,19 & 19 \\
\hline & B: (Viagem de uma semana para a & 124 & 0,81 & 81 \\
\hline
\end{tabular}




\begin{tabular}{|l|l|c|c|c|}
\hline \multirow{3}{*}{6} & Inglaterra: & & \\
$100 \%)$ & 59 & 0,38 & 38 \\
\hline \multirow{2}{*}{6} & $\begin{array}{l}\text { A: (Viagem de três semanas para } \\
\text { Inglaterra, } \\
\text { França e Itália: 5\%;Nada: 95\%) }\end{array}$ & $\begin{array}{l}\text { B: Viagem de uma semana para } \\
\text { Inglaterra: } \\
10 \% ; \text { Nada: } 90 \%) .\end{array}$ & 0,42 & 42 \\
\hline
\end{tabular}

Quadro 2 - Freqüências das repostas dos respondentes aos prospectos.

Fonte: Elaborado pelos autores.

Como pode ser constatado pela observação do quadro 2, os respondentes tomam decisões muitas vezes incompatíveis com atitudes baseadas no comportamento racional, fato que evidencia a existência dos conceitos fundamentais da Teoria do Prospecto como o efeito certeza. Dessa forma, é notável que as pessoas tomam suas decisões, baseada em deduções de que as escolhas são boas por causa dos resultados positivos que são apresentados e não por deduzirem que elas são boas por causa do método usado nas suas orientações de decisões e os meios pelos quais fizeram suas decisões.

Assim, o ganho certo oferecido visualizado nos prospectos 1, 3, 5 distorce a escolha da maioria das pessoas no sentido oposto ao previsto pela teoria tradicional de finanças, ou seja, verificar qual das alternativas proporciona o maior retorno. No prospecto $1,76 \%$ dos respondentes escolheram o ganho certo, no 3 e 5,81\%, resultados decorrentes da existência do chamado efeito certeza, fenômeno que revela que a maior parte da população não está disposta a correr risco para ganhar.

Percebe-se pelos resultados do prospecto 2, que a maioria dos respondentes,52\%, optou pela alternativa que proporciona um maior retorno, entretanto, a diferença é pequena em comparação com os demais, $48 \%$, que preferiram a outra alternativa.

Os resultados para o prospecto 6 demonstraram que existe a violação ao axioma da substituição não apenas para os resultados financeiros, mas para os não financeiros também, pois os respondentes parecem preferir as decisões mais certas do que as incertas, isso se justifica pelo fato de que $42 \%$ deles optarem por uma viagem de apenas uma semana, ao invés de uma outra de três semanas, pois a primeira apresenta uma probabilidade de ganho de $10 \%$, enquanto que a segunda de $5 \%$.

Quando o cenário é alterado para alternativas em que o investidor deve enfrentar alternativas que levam a perdas financeiras, prospecto 4, temos mais uma vez resultados conflitantes como o que é previsto pela teoria tradicional, pois os indivíduos deveriam optar pela alternativa onde a perda financeira é menor, entretanto não foi isso que foi constatado nos resultados desse prospecto. Os resultados demonstram que $65 \%$ escolheram a alternativa com maior perda financeira, enquanto que os demais, 35\%, preferiam a melhor escolha.

Isso ocorre porque as pessoas possuem forte disposição a correr riscos para evitar perdas, mesmo que impliquem, que na média perderão mais. Assim, pode-se visualizar que as pessoas não são avessas aos riscos, mas sim, avessas a perdas, fato que pode ser justificado pelo fato de que o estresse associado a uma perda ser significativamente maior que o prazer associado a um ganho da mesma proporção, o que implica na maioria dos investidores aceitar riscos, se isso trouxer a possibilidade de evitar ou limitar perdas potenciais.

Portanto, a busca por agentes econômicos por ganho certo e a tentativa de não obter prejuízo acarretam no efeito certeza, uma vez que os estudantes tenderam a dar maior peso às possibilidades com altas probabilidades de ocorrer.

Os quadros de 2 a 4 apresentam a freqüência das respostas aos problemas levantados no questionário da pesquisa, comparando simultaneamente os resultados encontrados para o GRUPO 
1 e o GRUPO 2. O número entre parênteses logo abaixo dos grupos refere-se ao tamanho da amostra.

No quadro 3 compara-se os resultados obtidos com os respondentes paro os problema $1 \mathrm{e}$ 2. Essa comparação confronta prospectos com três cenários e os resultados da amostra geral indicam uma violação do axioma da substituição na teoria da utilidade esperada.

\begin{tabular}{|c|l|c|c|}
\hline PROBLEMA & \multicolumn{1}{|c|}{ PROSPECTO } & $\begin{array}{c}\text { GRUPO 1 } \\
\mathbf{( 7 6 )}\end{array}$ & $\begin{array}{c}\text { GRUPO 2 } \\
\mathbf{( 7 8 )}\end{array}$ \\
\hline \multirow{2}{*}{1} & A: $(\$ 2500: 33 \% ; \$ 2400: 66 \% ; \$ 0: 1 \%)$ & $24 \%$ & $24 \%$ \\
& B: $(\$ 2400: 100 \%)$ & $76 \%$ & $76 \%$ \\
\hline \multirow{2}{*}{2} & A: $(\$ 2500: 33 \% ; \$ 0: 67 \%)$ & $50 \%$ & $35 \%$ \\
& B: $(\$ 2400: 34 \% ; \$ 0: 66 \%)$ & $50 \%$ & $65 \%$ \\
\hline
\end{tabular}

Quadro 3 - Frequiências das repostas dos respondentes aos prospectos para cada grupo analisado.

Fonte: Elaborado pelos autores.

Observa-se pelo quadro 3, que quando se analisa as respostas de cada grupo analisado para o prospecto 1, os resultados são iguais para os dois grupos, $76 \%$ dos respondentes preferiram ganho certo, e os demais, $24 \%$ optaram pela outra alternativa, resultados que são iguais a amostra geral. Enquanto para o prospecto 2, 65\% dos respondentes do grupo 2, preferiram a alternativa que proporcionava o menor retorno, fato que pode ser justificado por essa alternativa acarretar uma maior probabilidade de ganho, em comparação com a outra alternativa que possui um melhor resultado, já grupo 1, ficou dividido em $50 \%$ dos resultados para cada alternativa.

Os resultados dos respondentes para os problemas 3 e 4, podem ser visualizados no quadro 4 , no qual se compara os resultados obtidos para esses dois problemas.

\begin{tabular}{|c|l|c|c|}
\hline \multicolumn{1}{|c|}{ PROSPECTO } & $\begin{array}{c}\text { GRUPO 1 } \\
\text { (76) }\end{array}$ & $\begin{array}{c}\text { GRUPO 2 } \\
\text { (78) }\end{array}$ \\
\hline \multirow{2}{*}{3} & \multicolumn{1}{|c|}{ A: $(\$ 4000: 80 \% ; \$ 0: 20 \%)$} & $14 \%$ & $24 \%$ \\
& B:(\$3000:100\%) & $86 \%$ & $76 \%$ \\
\hline \multirow{2}{*}{4} & A: $(-\$ 4000: 80 \% ; \$ 0: 20 \%)$ & $61 \%$ & $69 \%$ \\
& B: $(-\$ 3000: 100 \%)$ & $39 \%$ & $31 \%$ \\
\hline
\end{tabular}

Quadro 4 - Freqüências das repostas dos respondentes aos prospectos para cada grupo analisado.

Fonte: Elaborado pelos autores.

Percebe-se pelo quadro 4, que ambos os grupos pesquisados preferiram o ganho certo para o problema 3, sendo uma escolha de $86 \%$ dos respondentes do grupo 1, e de $76 \%$ do grupo 2 , resultados que concordam com a escolha da maioria da amostra geral. Já para o prospecto 4 , foi obtido foi apresentado um problema em que os indivíduos deveriam optar pela alternativa 
onde a perda financeira é menor, entretanto não foi isso que foi constatado nos resultados desse prospecto nos dois grupos pesquisados.

Os resultados evidenciaram que para o grupo $1,61 \%$ dos pesquisados escolheram a alternativa com maior perda financeira, enquanto que os demais, $39 \%$, preferiam a melhor escolha, para o grupo 2, os resultados para as duas alternativas foram respectivamente, $69 \% \mathrm{e}$ $31 \%$.

No quadro 5, são apresentados e comparados os resultados obtidos para cada grupo pesquisado no que diz respeito aos problemas 5 e 6.

\begin{tabular}{|c|l|c|c|}
\hline \multirow{2}{*}{ PROBLEMA } & \multicolumn{1}{|c|}{ PROSPECTO } & \multicolumn{1}{|c|}{$\begin{array}{c}\text { GRUPO 1 } \\
\text { (76) }\end{array}$} & $\begin{array}{c}\text { GRUPO 2 } \\
\text { (78) }\end{array}$ \\
\hline \multirow{2}{*}{5} & $\begin{array}{l}\text { A: (Viagem de três semanas para Inglaterra, } \\
\text { França e Itália: 50\%;Nada: 50\%). }\end{array}$ & $14 \%$ & $24 \%$ \\
\cline { 2 - 4 } & $\begin{array}{l}\text { B: (Viagem de uma semana para a Inglaterra: } \\
100 \%)\end{array}$ & $86 \%$ & $76 \%$ \\
\hline \multirow{2}{*}{6} & $\begin{array}{l}\text { A: (Viagem de três semanas para Inglaterra, } \\
\text { França e Itália: 5\%;Nada: 95\%) }\end{array}$ & $39 \%$ & $37 \%$ \\
\cline { 2 - 4 } & $\begin{array}{l}\text { B: (Viagem de uma semana para Inglaterra: } \\
10 \% ; \text { Nada: 90\%). }\end{array}$ & $61 \%$ & $63 \%$ \\
\hline
\end{tabular}

Quadro 5 - Freqüências das repostas dos respondentes aos prospectos para cada grupo analisado. Fonte: Elaborado pelos autores.

Percebe-se quadro 5, que no problema 5, que $86 \%$ dos pesquisados do grupo 1 , e $76 \%$ do grupo 2, optaram pela viagem de apenas uma semana, pelo fato dela se apresentar como um ganho certo, enquanto que os demais, escolheram a outra alternativa. Já no prospecto 6 , o mesmo entendimento pode ser visualizado pelas respostas dos pesquisados, pois $61 \%$ dos respondentes do grupo 1, e $63 \%$ do grupo 2, optaram por uma viagem de apenas uma semana, ao invés de uma outra de três semanas, pois a primeira apresenta uma probabilidade de ganho de $10 \%$, enquanto que a segunda de $5 \%$.

Como pode ser constatado pela observação do quadro 5, os respondentes tomam decisões muitas vezes incompatíveis com atitudes baseadas no comportamento racional, deixando de verificar qual das alternativas proporciona o maior retorno, fato que pode ser justificado pelo fato de que os respondentes dos dois grupos, tanto nos problema 5 quanto no 6, preferirem as decisões mais certas do que as incertas.

Os resultados obtidos demonstraram que a educação financeira não influenciou a tomada de decisão da amostra pesquisada, pois foi possível constatar a presença de erros sistemáticos no processo de tomada de decisão, mesmo no grupo que apresentava uma melhor instrução financeira. Esse grupo, assim como ocorreu em toda amostra, deveria ter analisado qual das alternativas propostas proporcionava o maior retorno, e a partir dessa observação, escolher a melhor decisão, entretanto, o que foi visualizado é que os respondentes preferiram escolher as decisões que apresentavam um ganho mais certo.

\section{CONSIDERAÇÕES FINAIS}

As Finanças Comportamentais determinam que algumas variáveis econômicas não podem ser descritas pelas condições de equilíbrio da teoria moderna, uma vez que os agentes 
financeiros tomam decisões muitas vezes incompatíveis com aquelas baseadas em expectativas racionais. Este artigo investigou se os indivíduos que possuem conhecimento financeiro apresentam menos erros sistemáticos no processo de tomada de decisões.

Os resultados obtidos evidenciaram que o grupo que possuía uma melhor instrução financeira, assim como toda amostra, preferiu escolher as decisões que apresentavam um ganho mais certo, ao invés de analisar qual das alternativas propostas proporcionava o maior retorno, e a partir dessa análise, tomar a melhor decisão.

Diante dos resultados, pode-se concluir que a educação financeira não influenciou a tomada de decisão da amostra pesquisada, pois foi possível constatar a presença de erros sistemáticos no processo de tomada de decisão, mesmo no grupo que apresentava uma melhor instrução financeira.

Recomenda-se que para outras pesquisas, sejam formulados novos cenários experimentais, de modo que sejam envolvidos outros conceitos de finanças comportamentais, assim como, que seja aplicado esse estudo em outras amostras ou populações, a fim de se analisar o comportamento de outros respondentes em comparação com os resultados dessa pesquisa.

\section{REFERÊNCIAS}

ALDRIGHI, Dante Mendes; MILANEZ, Daniel Yabe (2005). Finança Comportamental e a Hipótese dos Mercados Eficientes. Revista de Economia Contemporânea, Rio de Janeiro, jan/abr. Disponível em < http://www.ie.ufrj.br/revista/lng/pt/exibe_resumo.php?codigo=123>. Acesso em 28 mar. 2010.

BUENO, Artur Franco. Os dividendos como estratégia de investimentos em ações. Revista contabilidade \& Finanças - USP, São Paulo, n. 28, p. 39-55, jan/abr, 2002. Disponível em $<$ http://www.eac.fea.usp.br/cadernos/completos/cad28/Revista\%2028\%20-

20parte\%20_3.pdf>. Acesso em 15 abr. 2010

CARVALHO JÚNIOR, César Valentim de Oliveira; ROCHA, Joséilton Silveira; BRUNI, Adriano Leal. $O$ aprendizado formal de controladoria e a minimização dos efeito framing: um estudo de decisões gerenciais envolvendo custos de oportunidade. In: Congresso de Controladoria e Contabilidade USP,2009, São Paulo. Anais do IX Congresso de Controladoria e Contabilidade, USP, 2009.

CASTRO JÚNIOR, Francisco Henrique Figueiredo de; FAMÁ, Rubens. (2002). As novas finanças e a teoria comportamental no contexto da tomada de decisão sobre investimentos. Caderno de Pesquisas em Administração. v.9, abril / julho (2). Disponível em $<$ http://www2.ifes.com.br/webifes/conhecimento/Files/ADMINISTRA\%C7\%C3O\%20FINA NCEIRA\%20e\%20CUSTOS/Finan\%E7as\%20Comportamentais\%20e\%20Mercado $\% 20 \mathrm{de} \% 2$ 0Capitais/Artigos\%20Nacionais/Novas\%20Finan\%E7as\%20e\%20Teoria\%20Comportamenta 1.pdf>. Acesso em 29 mar. 2010.

COSTA, Renata Borges, et al. Otimismo e excesso de confiança: um estudo do perfil comportamental dos indivíduos á luz das finanças comportamentais. Disponível em < http://www.ead.fea.usp.br/semead/12semead/resultado/trabalhosPDF/678.pdf

>. Acesso em 12 abr. 2010. 
HALFELD, Mauro; TORRES, Fábio de Freitas Leitão, (2001). Finanças Comportamentais: aplicações no contexto brasileiro. RAE - Revista de Administração de Empresas, Abr./Jun, São Paulo. Disponível em <http://www16.fgv.br/rae/artigos/392.pdf>. Acesso em 11 abr. 2010.

KIMURA, Herbert (2003). Aspectos Comportamentais Associados às Reações do Mercado de Capitais. Revista de Administração de Empresas - Eletrônica, v. 2, n. 1, jan-jun. Disponível em <http://www16.fgv.br/rae/artigos/1880.pdf>. Acesso em 25 abr. 2010.

MACEDO JÚNIOR, Jurandir Sell. Teoria do Prospecto: uma investigação utilizando simulação de investimentos. 2003.218 f. Tese (Doutorado em Engenharia de Produção) Universidade Federal de Santa Catarina, Florianópolis. Disponível em <http://www.tede.ufsc.br/teses/PEPS3749.pdf>. Acesso em 12 abr. 2010.

MEDEIROS, Regiane Delfino (2005). Efeito Doação, Efeito Disposição e Rentabilidade: Uma Análise Empírica em Finanças Comportamentais. TCC Graduação - Universidade Federal de Santa Catarina, Florianópolis. Disponível em < http://www.portalcse.ufsc.br/ gecon/coord_mono/2005.2/Regiane\%20D.\%20Medeiros.pdf >. Acesso em 28 mar. 2010

MILANEZ, Daniel Yabe. (2003). Finanças Comportamentais no Brasil. São Paulo: Faculdade de Economia e Administração da Universidade de São Paulo (FEA - USP), Dissertação de Mestrado. $\quad$ Disponível em http://www.teses.usp.br/teses/disponiveis/12/12140/tde-09022004-130012/ >. Acesso em 05 abr. 2010.

OLIVEIRA, Eliane de SILVA, Sandra Maria da SILVA, Wesley Vieira da (2005). Finanças Comportamentais: um estudo sobre o perfil comportamental do investidor e do propenso investidor. In: II Seminário de Gestão de Negócios da FAE Business School, 2005, Curitiba - $\quad$ Paraná. $\quad$ Disponível em http://www.fae.edu/publicacoes/pdf/IIseminario/gestao/gestao_11.pdf >. Acesso em 17 abr. 2010.

RAMOS, André Luiz (2007). Análise do Efeito Comportamental no Índice Bovespa: Um estudo interdisciplinar. Dissertação de Mestrado. Pontifícia Universidade Católica - SP, São Paulo. Disponível em $<$ http://www.sapientia.pucsp.br/tde_busca/arquivo.php?codArquivo=4091>. Acesso em 18 abr. 2010 .

ROGERS, Pablo; FAVATO, Verônica; SECURATO, José Roberto. Efeito educação financeira no processo de tomada de decisões em investimentos: um estudo a luz das finanças comportamentais. $\quad$ Disponível em <http://www.anpcont.com.br/site/docs/congressoII/04/MFC194.pdf>. Acesso em 30 mar. 2010 .

SANTOS, José Augusto Rodrigues dos; SANTOS, José Odálio dos. (2005). Mercado de Capitais: Racionalidade Versus Emoção. Disponível em < http://www.congressousp.fipecafi.org/artigos42004/86.pdf>. Acesso em 15 mar. 2010. 
YOSHINAGA, Cláudia Emiko et al (2004) . Finanças Comportamentais: Uma Introdução. V I I $\mathrm{S}$ E $\mathrm{M} \quad \mathrm{E} \quad \mathrm{A}$ D. USP $\quad-$ São Paulo. Disponível em $<$ http://www.ead.fea.usp.br/semead/7semead/paginas/artigos\%20recebidos/Finan\%E7as/FIN2 4_-_Finan\%E7as_Comportamentais.PDF>. Acesso em 25 abr. 2010. 